\title{
Direct measurement of particle formation and growth from the oxidation of biogenic emissions
}

\author{
T. M. VanReken ${ }^{1}$, J. P. Greenberg ${ }^{2}$, P. C. Harley ${ }^{2}$, A. B. Guenther ${ }^{2}$, and J. N. Smith ${ }^{2}$ \\ ${ }^{1}$ Advanced Study Program, National Center for Atmospheric Research, Boulder, CO, USA \\ ${ }^{2}$ Atmospheric Chemistry Division, National Center for Atmospheric Research, Boulder, CO, USA
}

Received: 23 May 2006 - Published in Atmos. Chem. Phys. Discuss.: 17 July 2006

Revised: 21 September 2006 - Accepted: 28 September 2006 - Published: 29 September 2006

\begin{abstract}
A new facility has been developed to investigate the formation of new particles from the oxidation of volatile organic compounds emitted from vegetation. The facility consists of a biogenic emissions enclosure, an aerosol growth chamber, and the associated instrumentation. Using the facility, new particle formation events have been induced through the reaction of ozone with three different precursor gas mixtures: an $\alpha$-pinene test mixture and the emissions of a Holm oak (Quercus ilex) specimen and a loblolly pine (Pinus taeda) specimen. The results demonstrate the variability between species in their potential to form new aerosol products. The emissions of $Q$. ilex specimen resulted in fewer particles than did $\alpha$-pinene, although the concentration of monoterpenes was roughly equal in both experiments before the addition of ozone. Conversely, the oxidation of P. taeda specimen emissions led to the formation of more particles than either of the other two gas mixtures, despite a lower initial terpenoid concentration. These variations can be attributed to differences in the speciation of the vegetative emissions with respect to the $\alpha$-pinene mixture and to each other. Specifically, the presence of $\beta$-pinene and other slower-reacting monoterpenes probably inhibited particle formation in the $Q$. ilex experiment, while the presence of sesquiterpenes, including $\beta$-caryophyllene, in the emissions of the P. taeda specimen were the likely cause of the more intense particle formation events observed during that experiment.
\end{abstract}

\section{Introduction}

Biogenic secondary organic aerosols (SOA) are thought to be a significant contributor to total aerosol mass globally, and are likely to be the dominant source of particulate matter in some remote continental areas (Andreae and Crutzen, 1997;

Correspondence to: T. M. VanReken

(vanreken@ucar.edu)
Griffin et al., 1999a). As such, they are likely to have significant impacts on the Earth's radiative balance, both on global and regional scales. Like other aerosols, SOA can scatter or absorb incoming solar radiation and thus contribute to the "direct aerosol effect". Additionally, biogenic SOA can modify cloud properties through its potential contribution to the population of cloud condensation nuclei $(\mathrm{CCN})$. These modifications to cloud properties can in various ways also affect the fate of incoming solar radiation and are known as the "indirect aerosol effects". In the most recent assessment by the Intergovernmental Panel on Climate Change (2001), these aerosol effects were classified as having only a "Very Low" level of scientific understanding. Improving our understanding of the role of aerosols in the climate system requires first a greater knowledge of the mechanisms leading to aerosol formation in the atmosphere. Despite extensive ongoing research, there is still much to learn about the processes leading to the formation of biogenic SOA (Kanakidou et al., 2004). Only recently are models being developed that attempt to predict the formation and growth of biogenic SOA under ambient conditions (e.g., Boy et al., 2006). The robustness of such models has not yet been demonstrated, nor are they yet able to adequately forecast the physical and chemical properties of the resulting aerosol. Such a predictive capability is necessary in order to effectively incorporate biogenic SOA into the larger-scale models used to study regional air quality and global climate change.

Secondary organic aerosol is formed when volatile organic compounds (VOCs), either biogenic or anthropogenic in origin, are oxidized in the atmosphere to form less volatile products. Some fraction of the oxidized material partitions to the particle phase, either by condensing onto the pre-existing aerosol or by forming new particles. Systematic field observations have proven valuable in establishing what classes of biogenic compounds are most likely to be precursors of SOA and under what conditions particle formation events are likely to occur (Kulmala et al., 2004, and references

Published by Copernicus GmbH on behalf of the European Geosciences Union. 
therein). Notably, however, field observations have also highlighted gaps in our understanding of biogenic emissions and their subsequent fate. For example, researchers studying a forested site in the Sierra Nevada mountains in California have concluded that an additional, undetermined, class of reactive biogenic VOCs must exist in the forest canopy, based on unexplained loss of ozone (Goldstein et al., 2004) and the presence of excess oxidized VOCs (Holzinger et al., 2005).

Laboratory studies of SOA formation from known biogenic precursors are complementary to field observations. For this reason the oxidation of biogenic VOCs has been studied in aerosol growth chambers for many years. Yu et al. (1999) characterized the gaseous and particulate products of monoterpene ozonolysis, and more recent studies have determined the potential for this class of biogenic compounds to oxidize to condensable products under a wide variety of conditions (e.g., Bonn and Moortgat, 2002). Other laboratory studies have recently investigated the aerosol-forming potential of other biogenic compounds, including isoprene and the sesquiterpenes. Griffin et al. (1999a, b) found that sesquiterpene oxidation resulted in significantly higher aerosol yields (17-67\%) than did monoterpenes (2-23\%), making sesquiterpenes a significant contributor to biogenic SOA despite very low atmospheric concentrations. Claeys et al. (2004) and Kroll et al. (2005) have recently demonstrated that biogenic SOA also forms via the oxidation of isoprene; yields in these experiments were quite low $(\sim 3 \%)$, but isoprene accounts for $\sim 50 \%$ of the global burden of nonmethane hydrocarbons, making it a significant contributor even at such low yields.

These chamber studies generally focus on characterizing the dependence of aerosol formation on various process variables, and therefore are designed to isolate those variables to the degree possible. This usually results in a considerable simplification of the system as compared to the ambient atmosphere. Usually, only a single organic compound is used in any given experiment, and only a single oxidizing compound. Scavenging compounds are frequently used to consume any competing oxidants that might be formed during the experiments. These procedures are necessary for experiments whose goal is to characterize SOA formation pathways. However, because the mechanisms for aerosol formation from biogenic VOCs are complex and highly nonlinear, it is uncertain to what degree the dependencies observed in chamber studies can be extrapolated to conditions more closely resembling the complexity of the ambient atmosphere. Studies exploring this complexity are also important for three reasons: 1) they serve as verification that the results of more idealized studies are comparable to what is observed under more realistic conditions; 2) they provide more immediate, "big picture" answers to the needs of the climate modeling community, in this case by characterizing the aerosol production capability of different plant species without requiring detailed knowledge of the emitted compounds; and 3 ) they are potentially very useful for finding and character- izing the unidentified compounds required by the analyses of Goldstein et al. (2004).

Two recent studies have addressed these types of questions by using direct biogenic emissions as the precursor for aerosol formation rather than a single compound. McFiggans et al. (2004) formed new particles by exposing the emissions of Laminaria macroalgae to elevated ozone concentrations. These particles were very similar in morphology and composition to particles generated via the oxidation of diiodomethane $\left(\mathrm{CH}_{2} \mathrm{I}_{2}\right)$ and molecular iodine $\left(\mathrm{I}_{2}\right)$. Joutsensaari et al. (2005) observed a new particle formation event when specimens of white cabbage (Brassica oleracea) were placed in an environmental chamber and exposed to ozone. They found particle formation rates similar to those observed in field studies, but that their observed aerosol growth rate was much greater. In the latter study, VOC concentrations were increased by exposing the plants to methyl jasmonate, a signaling compound that induces terpenoid emissions. The current study takes a similar approach to that of Joutsensaari et al. (2005), but without any artificial enhancement of VOC emissions. A facility has been developed to explore the potential of emissions from different plant species to form SOA under atmospherically relevant conditions. Using this facility, new particles were formed via the ozonolysis of three gas mixtures: a dilute mixture of $\alpha$-pinene in air, emissions from a Holm oak (Quercus ilex) specimen, and emissions from a loblolly pine (Pinus taeda) specimen.

\section{Experimental system}

\subsection{Facility description}

The new facility assembled for this study (Fig. 1) consists primarily of an aerosol growth chamber and a biogenic emissions enclosure. The aerosol growth chamber is a $\sim 1.5 \mathrm{~m}^{3}$ bag made of $0.05 \mathrm{~mm}$ FEP Teflon film suspended in a steel enclosure. The enclosure protects the bag and prevents light exposure. Reactants enter the chamber and samples are withdrawn through two manifolds at opposite sides of the chamber. The manifolds each include four access ports, one of which has been enlarged for mounting a temperature and relative humidity probe (Vaisala Model HMP50). The rest are drilled to allow standard $16 \mathrm{~mm}$ tubing to be press-fit into the port.

The biogenic emissions enclosure can be customized to meet the needs of individual experiments. For this study, an enclosure was chosen that has a volume of 101 and is designed to collect the emissions from a living plant specimen roughly the size of a small tree branch. It consists of a cylinder of $0.10 \mathrm{~mm}$ Teflon sheeting, sealed at one end to a $16 \mathrm{~mm}$ Teflon plate. This plate supports the enclosure and serves as a manifold through which air passes into and out of the enclosure. The opposite end of the enclosure is wrapped around the base of the branch as tightly as is practical to minimize 


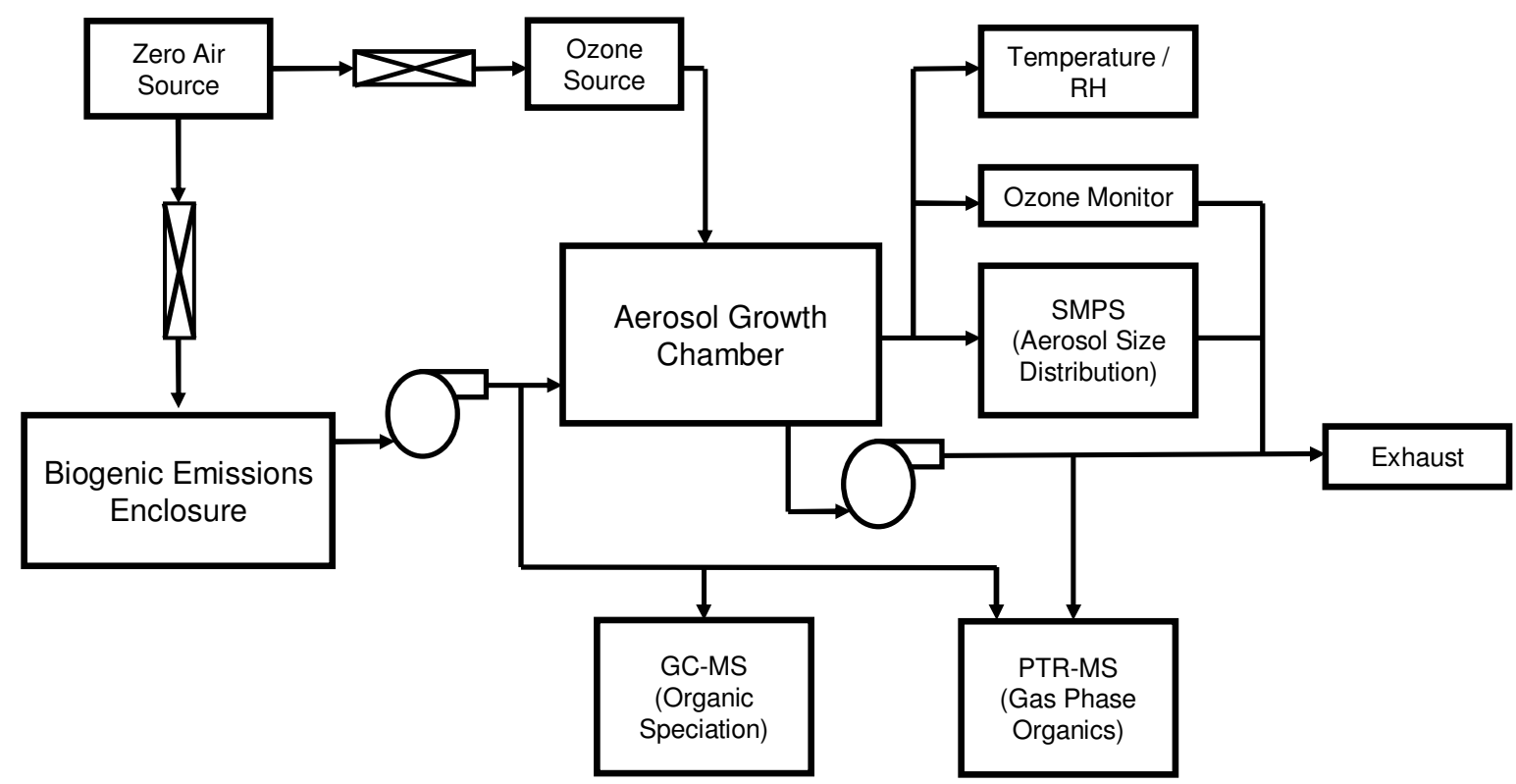

Fig. 1. Schematic of the experimental apparatus used in these experiments. Details of the apparatus and the sampling instrumentation are provided in the text.

leaks without damaging the plant. A $1000 \mathrm{~W}$ quartz-halogen high intensity discharge lamp suspended over the enclosure provided $\sim 700 \mu \mathrm{mol} \mathrm{m}^{-2} \mathrm{~s}^{-1}$ photosynthetically active radiation during a $12-13 \mathrm{~h}$ photoperiod, ensuring stable photosynthetic activity and VOC emissions. The proximity of the lamp to the biogenic emissions enclosure is estimated to increase the temperature inside the enclosure by $\sim 5 \mathrm{~K}$ relative to the aerosol growth chamber and the rest of the laboratory.

In contrast with most chamber studies of aerosol formation and growth, a constant flow through the system was maintained during these experiments. Both the aerosol growth chamber and the biogenic emissions enclosure were supplied with air from a Pure Air Generator (Aadco Model 737). This generator was used to keep the system at positive pressure so that any leaks were from the system to the surrounding room, rather than vice versa. As indicated in Fig. 1, the aerosol growth chamber is fed via two lines. The first arrives to the chamber directly from the pure air generator; an ultraviolet ozonizer was present in this line whose intensity could be adjusted to control the concentration of ozone entering the aerosol growth chamber. The flow rate of this stream was controlled using a rotometer and checked prior to each experiment using a bubble flow meter (Gilibrator, Gilian Instrument Corp.). The second stream entering the aerosol growth chamber was supplied from the biogenic emissions enclosure. This flow was controlled with a needle valve and checked with a bubble flow meter prior to each experiment. A diaphragm pump was required to transfer air from the biogenic enclosure to the growth chamber; tests with an empty branch enclosure demonstrated that the pump generated few particles $\left(<2 \mathrm{~cm}^{-3}\right)$, and those generated were at the high end of the measured size range ( $>200 \mathrm{~nm})$. No particle filter was placed between the biogenic emissions enclosure and the aerosol growth chamber out of concern that "sticky" VOCs would be trapped by the filter along with any particles.

\subsection{Sampling instrumentation}

The primary goal of these experiments was to determine whether new particle formation can occur readily from the oxidation of biogenic emissions. This required monitoring reactant concentrations entering and exiting the aerosol growth chamber and the aerosol size distribution leaving the chamber. Ozone concentrations were measured using a 2B Technologies Model 202 ozone monitor, which had a time resolution of $5 \mathrm{~s}$. Biogenic VOC concentrations were monitored with a proton-transfer-reaction mass spectrometer (PTR-MS) constructed in house at NCAR (Hanson et al., 2002), based on a technique first developed by Lindinger et al. (1998). The proton transfer reaction is a very soft ionization technique, so that the fragmentation of large organic molecules is minimized. This gives the PTR-MS increased sensitivity to VOCs such as monoterpenes and sesquiterpenes, but makes it difficult to differentiate samples of the same molecular mass. Thus, while the instrument can discriminate between monoterpenes and sesquiterpenes, $\alpha$-pinene and $\beta$-pinene cannot be distinguished. During these experiments, the PTR-MS was operated exclusively in selected ion mode. With a time resolution of $10 \mathrm{~s}$, ions were monitored with mass-to-charge ratios $(\mathrm{m} / \mathrm{z})$ consistent with monoterpenes $(m / z=81,137)$ and sesquiterpenes $(m / z=205)$. Ions for potential reaction products from the 

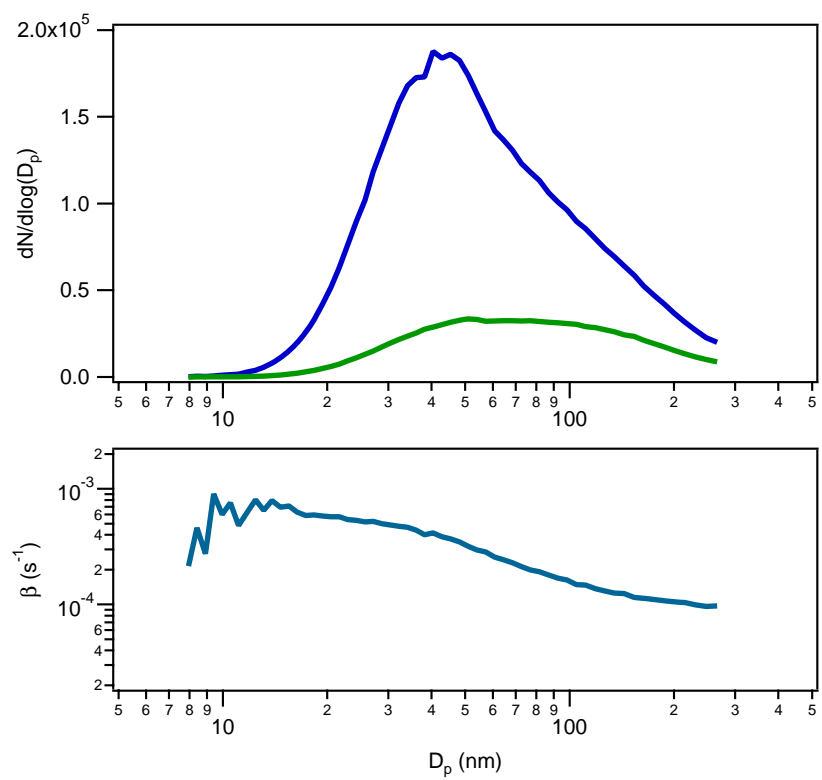

Fig. 2. Results of the wall loss characterization experiment. (a) Aerosol number size distributions entering (blue) and leaving (green) the aerosol growth chamber at steady state under the same flow conditions used throughout the study. (b) Calculated values of $\beta\left(d_{p}\right)$ for the aerosol growth chamber based on Eq. (2) and the data presented in (a).

ozonolysis of these species were not monitored in this study. Data from both the ozone monitor and the PTR-MS were averaged over two minutes to reduce the statistical variability. With both instruments, switching between the input and output sampling streams was done manually, and output concentrations were monitored most of the time. When sampling the output flow from the chamber, the sample was taken downstream of the purge pump.

In order to obtain more detailed speciation of the VOCs emitted by the plant specimens, samples of the gas mixture leaving the biogenic emissions chamber were analyzed using gas chromatography-mass spectrometry (GC-MS). Using a small flow-controlled pump (Pocket Pump 210, SKC, Eighty-Four, PA) samples of approximately 61 were collected onto solid adsorbent cartridges containing Tenax GR (Supelco, Bellefonte, PA). Cartridges were thermally desorbed and analyzed by GC-MS using the methodology previously described by Greenberg et al. (1999).

Aerosol size distributions over a diameter range of 10 $200 \mathrm{~nm}$ were measured every four minutes using a scanning mobility particle sizer (SMPS), consisting of a long-column differential mobility analyzer (DMA) in series with a condensation particle counter (CPC, TSI Model 3020). The polydisperse and monodisperse aerosol flows in the DMA were maintained at $1.1 \mathrm{lpm}$, and the sheath and excess flows were kept at $10 \mathrm{lpm}$ with a recirculating blower. The CPC required $0.3 \mathrm{lpm}$ of the monodisperse flow; the remaining $0.8 \mathrm{lpm}$ was discarded.

\subsection{Wall loss analysis}

An important factor to consider in any chamber study is the effect of losses to the walls on the VOC concentrations, and, more importantly here, on the aerosol size distribution. To characterize the wall losses for aerosols in the new aerosol growth chamber, an experiment was performed during which a stable, polydisperse ammonium sulfate aerosol was fed to the chamber and the particle size distribution exiting the chamber was monitored continuously for several hours (using the SMPS system described in Sect. 2.2). The flow conditions were identical to the particle formation experiments. After $\sim 4 \mathrm{~h}$ the particle size distribution had stabilized, corresponding to the approximate residence time in the growth chamber. The average size distributions for the aerosols entering and exiting the growth chamber at equilibrium are presented in Fig. 2a.

These data were used to obtain a size-dependent wall loss coefficient, $\beta(\mathrm{dp})$, defined by Fuchs (1964) as

$\frac{d n\left(d_{p}, t\right)}{d t}=-\beta \cdot n\left(d_{p}, t\right)$

where $n\left(d_{p}, t\right)$ is the particle size distribution function in the chamber at time $t$. To obtain $\beta\left(d_{p}\right)$ from the data obtained in the wall loss experiment, the aerosol chamber was modeled as a continuous stirred-tank reactor (Levenspiel, 1972). Under this assumption,

$\beta\left(d_{p}\right)=\frac{Q}{V} \cdot\left(\frac{n_{0}\left(d_{p}\right)}{n\left(d_{p}\right)}\right)$

where $Q$ is the flow rate into the aerosol growth chamber, $V$ is the volume of the chamber, and $n_{0}\left(d_{p}\right)$ is the particle size distribution function entering the chamber. The measured values of $\beta\left(d_{p}\right)$ from this analysis are presented in Fig. $2 \mathrm{~b}$, and are in good agreement with the theory developed by Crump and Seinfeld (1981). They were used to correct the size distributions measured during the biogenic aerosol experiments.

\subsection{Experimental design}

As was noted above, the facility used in this study operates with air passing continuously through the system. In preparation for each experiment, clean, particle-free air was flushed through the aerosol growth chamber for several hours, until there were no particles observed in air exiting the chamber. At that time the biogenic VOCs were added by passing air from the biogenic emissions enclosure to the aerosol growth chamber at a rate of $1.3 \mathrm{lpm}$. A second flow of particle-free "zero" air continued to be supplied to the growth chamber at a rate of $5.5 \mathrm{lpm}$. These flow rates correspond to a residence time inside the aerosol growth chamber of approximately four hours. Simultaneously, sample flows totaling $5.5 \mathrm{lpm}$ were removed from the chamber. This total includes $1.1 \mathrm{lpm}$ required by the SMPS system, $0.4 \mathrm{lpm}$ required by 
the ozone monitor, and a $4.0 \mathrm{lpm}$ purge flow vented to the building exhaust system. The purge flow was controlled using a critical orifice upstream of a vacuum pump, and was included in the system primarily to keep the residence time of the chamber in the desired range. As was noted above, the chamber was intentionally over-pressured, so that any leaks would be from the chamber into the laboratory rather than in the opposite direction.

When the VOC concentration in the growth chamber reached $\sim 80 \%$ of its input concentration, the ozone addition was initiated by turning on the ultraviolet ozonizer in line with the $5.5 \mathrm{lpm}$ input flow. After a brief warm-up period, the ozonizer consistently fed ozone to the aerosol chamber at a concentration of $50 \mathrm{ppb}$ during each experiment (this concentration, and all other reported input concentrations, take into account the extra dilution caused by mixing the two input flows). Neither the temperature nor the relative humidity was controlled actively during this study. The laboratory in which the experiments were conducted was temperature-controlled, thereby maintaining the temperature in the aerosol growth chamber at $\sim 298 \mathrm{~K}$ during the day; the temperature decreased by $\sim 1.5 \mathrm{~K}$ each night. The "zero" air produced by the pure air generator was quite dry, but the humidity in the aerosol growth chamber fluctuated by several percent due to the plants' transpiration cycles.

Three experiments were performed for this study, one using an $\alpha$-pinene gas mixture as the VOC source, one using a Holm oak specimen ( $Q$. ilex), and one using a loblolly pine specimen ( $P$. taeda). The experiment with $\alpha$-pinene was included primarily to provide a baseline for comparison with the other studies, and to confirm that particle formation would be observed under conditions where events have occurred in earlier studies (e.g., by VanReken et al., 2005). For this experiment only, the biogenic emissions enclosure was replaced with a dilution system that mixed an $840 \mathrm{ppb}$ $\alpha$-pinene calibration standard with zero air to obtain an $\alpha$ pinene concentration of $6 \mathrm{ppb}$ entering the aerosol growth chamber. Except for replacing the biogenic emissions enclosure, this experiment was performed using the same methodology as the two experiments using plant specimens. However, it was not possible to control the magnitude of incoming VOC concentrations as closely during the plant experiments, or to keep those concentrations constant over time.

The first plant specimen examined in the study was the evergreen oak, $Q$. ilex. This species was chosen because it is a major forest component in Spain, Portugal and other Mediterranean countries and because it has very high rates of monoterpene emission that are quite sensitive to the level of ambient radiation (Staudt and Seufert, 1995). The emitted monoterpenes from $Q$. ilex are predominantly $\alpha$-pinene, $\beta$ pinene, sabinene, myrcene and limonene with minor contributions from $\alpha$-thujene, camphene, $\gamma$-terpinene, p-cymene, $\beta$-ocimene and linalool. There is considerable intraspecific variability (Staudt et al., 2001).
The emissions source for the second biogenic experiment was a loblolly pine sapling (P. taeda). This species was chosen because of its prevalence in the southeastern United States and because it is known to have substantial emissions of sesquiterpenes as well as monoterpenes (Stroud et al., 2005). The emission rates of monoterpenes from P. taeda are lower than from $Q$. ilex (Karl et al., 2005). Less is known about the light dependence of VOC emissions from $P$. taeda compared with $Q$. ilex. While its emissions of monoterpenes are not thought to be strongly light dependent, there is some evidence that sesquiterpene emissions from P. taeda are at least partly light dependent (P. Harley, unpublished data). Hansen and Seufert (2003) have shown that sesquiterpene emissions can be light dependent, using emissions measurements from orange tree specimens. Certain sesquiterpenes emitted by needles of loblolly pine, including $\beta$-caryophyllene, are more reactive with ozone than are monoterpenes and their oxidation products are less volatile (Griffin et al., 1999b). Thus, it has been proposed that sesquiterpenes emitted by conifers play a direct role in the formation of new particles in boreal regions (Bonn and Moortgat, 2003).

\section{Results}

\section{$3.1 \alpha$-Pinene}

The results of the $\alpha$-pinene experiment are presented in Fig. 3. During the experiment, the temperature remained at $298 \pm 1 \mathrm{~K}$, and the relative humidity remained below $10 \%$ (Fig. 3a). The concentration of the monoterpene source at the entrance to the aerosol growth chamber was maintained at $6 \mathrm{ppb}$ by diluting an $\alpha$-pinene calibration gas to the desired concentration (see Sect. 2.4). At steady state, the monoterpene and ozone concentrations leaving the aerosol growth chamber were $3 \mathrm{ppb}$ and $46 \mathrm{ppb}$, respectively (Fig. 3b).

Approximately three hours after the initial addition of ozone, a particle formation event occurred (Fig. 3c-d). The total particle concentration exiting the chamber increased for three hours until reaching a maximum of $450 \mathrm{~cm}^{-3}$, at which point the mode of the size distribution was $\sim 50 \mathrm{~nm}$. The particle growth rate was $\sim 12 \mathrm{~nm} \mathrm{~h}^{-1}$. The particle number concentration then decreased steadily for nine hours, with no clear trend in the mode diameter, before beginning to increase again. Over the subsequent three hours the concentration again increased to $400 \mathrm{~cm}^{-3}$, with the mode diameter remaining near $50 \mathrm{~nm}$. While the particle number concentration peaked three hours after the initial onset of the particle formation event, the total aerosol volume continued to increase for an additional six hours (Fig. 3d). Indeed, no decrease in aerosol volume was observed until the largest particles grew beyond the range measured by the SMPS. The volume began to increase again as the particle number 

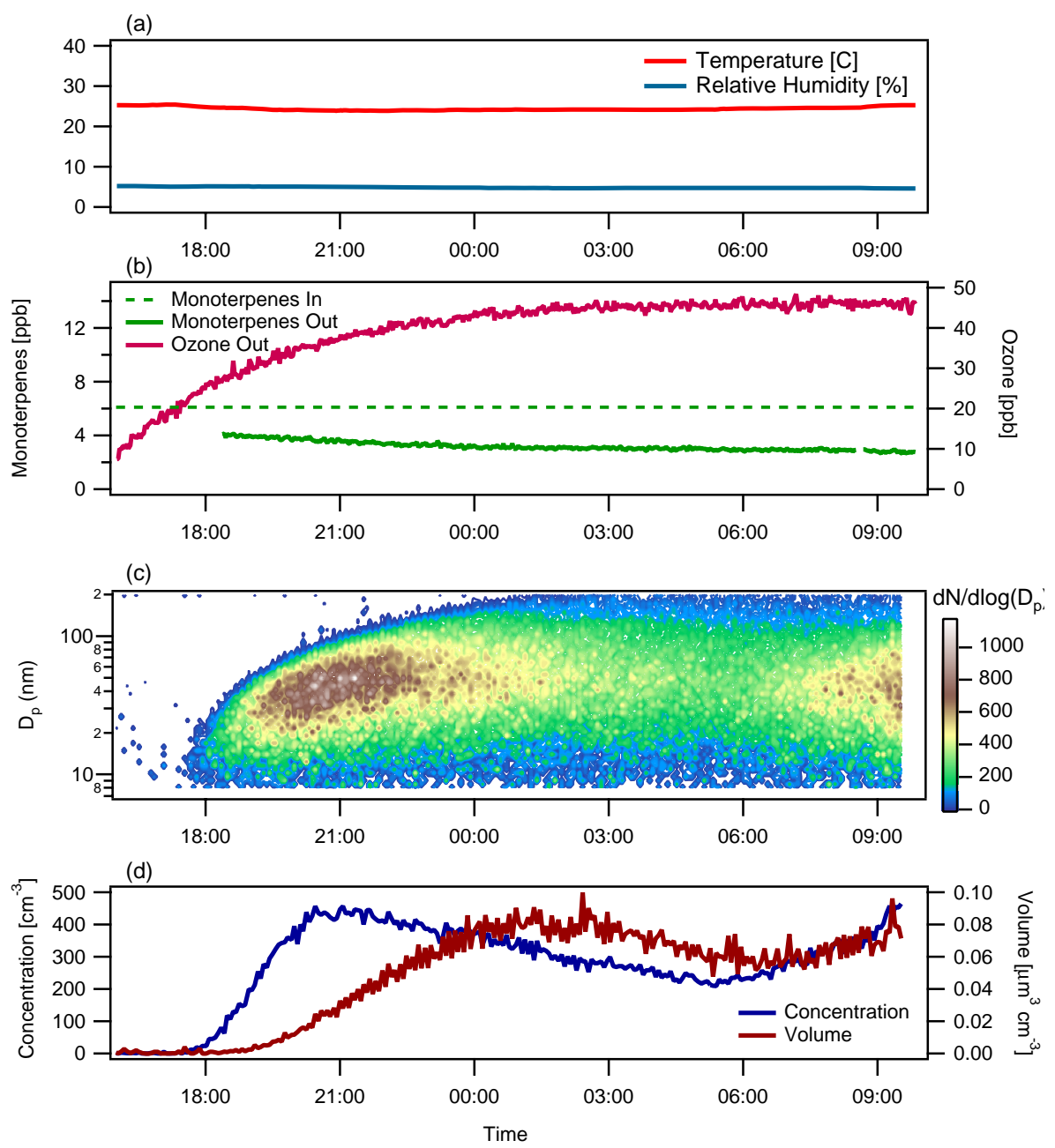

Fig. 3. Results from the $\alpha$-pinene experiment. (a) Temperature and relative humidity in the aerosol growth chamber. (b) Gas phase concentrations entering and leaving the aerosol growth chamber. Green dotted line is the monoterpene concentration entering the chamber, and the green solid line is the monoterpene concentration measured at the chamber exit. Solid purple line is the ozone concentration at the chamber exit. (c) Aerosol number size distribution exiting the aerosol growth chamber. (d) Total aerosol number concentration (solid blue line), and aerosol volume (solid red line) calculated from the size distribution data in (c).

concentration increased starting at $\sim 05: 00$ UTC. The experiment was stopped $18 \mathrm{~h}$ after its start.

The oscillatory behavior observed in the particle formation processes during the $\alpha$-pinene experiment is characteristic of a continuous-flow system with a steady source of condensable material. It has been observed and explained previously (Badger and Dryden, 1939; McGraw and Saunders, 1984). The behavior can be understood by considering the competition for condensable material between the growth of pre-existing particles and the formation of new particles. At the start of the experiment, there was no significant sink for the condensable material, so new particle formation was favored. For three hours the available surface area remained low enough the new particles continued to be formed, and hence the number concentration continued to increase. After those three hours however, the condensational sink became large enough that particle formation was no longer fa- vored. Material continued to condense (and hence the aerosol volume continued to increase), but few new particles were formed. During this period, particles continued to be removed from the system, by removal to the sampling system and via wall losses. Eventually, the available condensational sink decreased enough that particle formation again began to occur, and the number concentration again increased. In this system, the aerosol volume should remain constant once it reached its equilibrium level. This behavior was not observed during this experiment, though this was likely due to an insufficient measurement range for the SMPS. While it cannot be confirmed with the available data, it is likely that the maximum volume reached at $\sim 02: 00$ was the equilibrium volume for the system, and the subsequent decrease was due to the uncounted particles beyond the measurement range of the SMPS. 

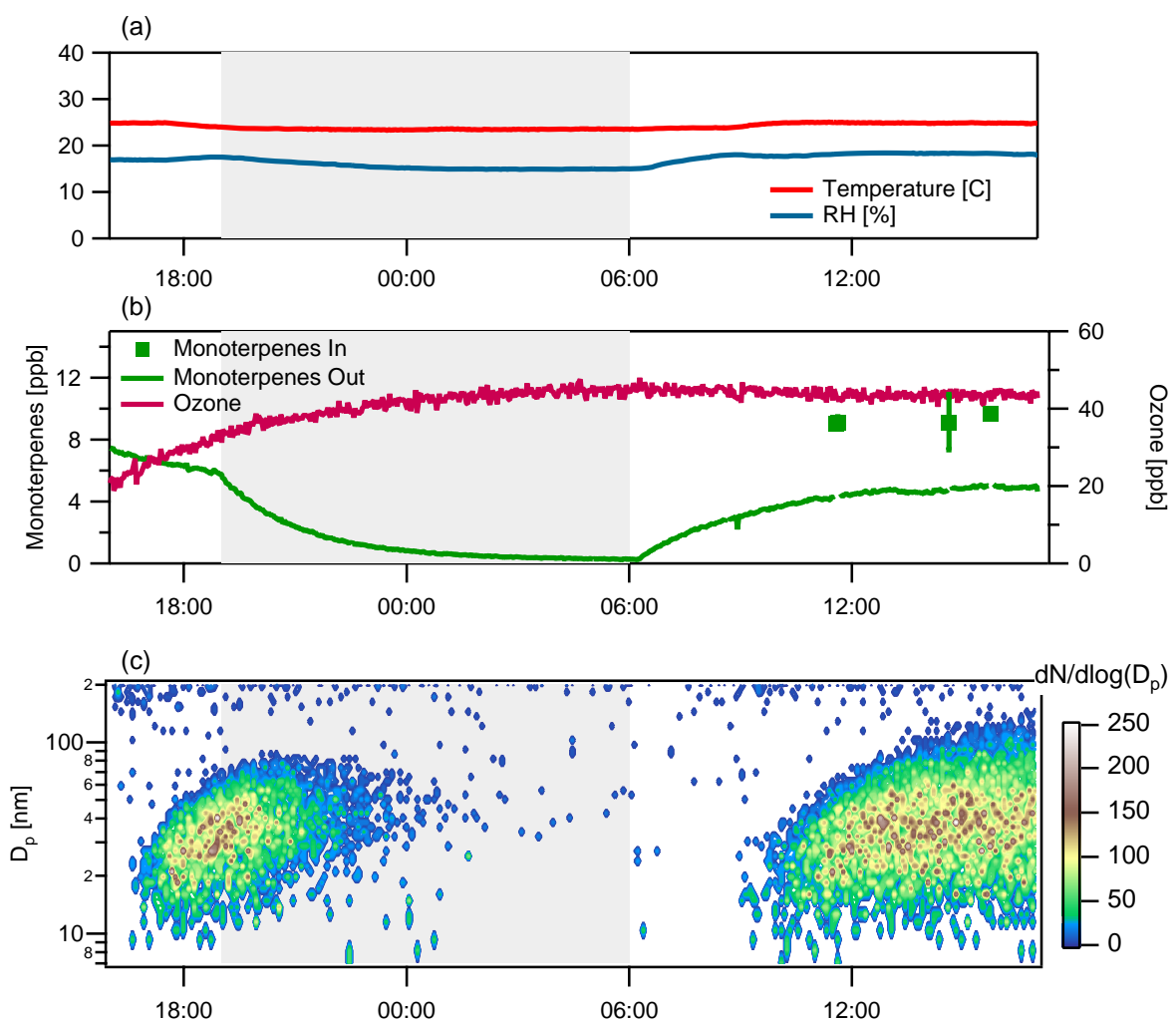

(d)

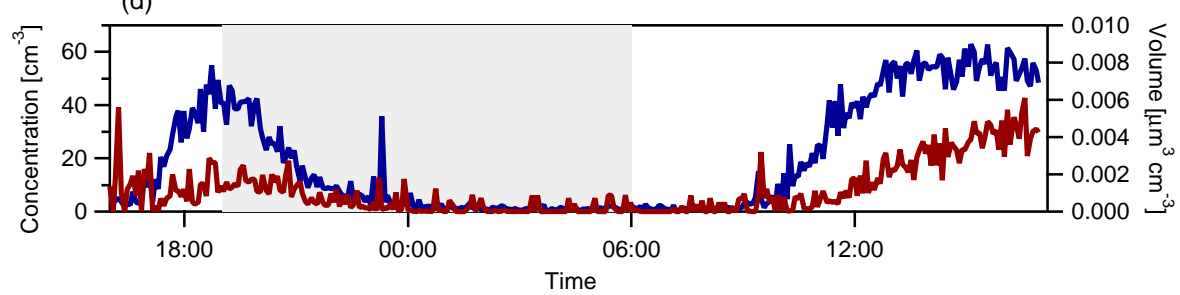

Fig. 4. Results of the $Q$. ilex experiment. Grey shading indicates the period when the light illuminating the biogenic emissions enclosure was switched off. (a) Temperature and relative humidity as in Fig. 3a. (b) Gas phase concentrations. As in Fig. 3b, except that measured monoterpene concentrations entering the aerosol growth chamber are presented as green squares. (c) Aerosol number size distribution exiting the aerosol growth chamber, as in Fig. 3c. (d) Total aerosol number concentration and volume, as in Fig. 3d.

\subsection{Holm oak (Quercus ilex)}

Figure 4 shows results of the $Q$. ilex experiment. The time series plots begin approximately two hours after the initial addition of ozone to the system, but before any new particle formation occurred. The temperature inside the chamber behaved as in the $\alpha$-pinene experiment, remaining at $298 \pm 1 \mathrm{~K}$, with slightly cooler temperatures at night when the lab was empty (grey shading in Fig. 4 indicates the period during which the plant was not illuminated). The relative humidity in the chamber varied with the transpiration cycle of the plant specimen; it was $18 \pm 2 \%$ during the day and decreased to $\sim 14 \%$ at night. Measurements on the second day indicated that the monoterpene concentration entering the aerosol growth chamber was $9 \mathrm{ppb}$. Though no measurements of the input monoterpene concentrations were made overnight (when the plant was not illuminated), the results of Staudt and Seufert (1995) and the rapid decline of the output monoterpene concentration support the assumption that the nighttime emissions of monoterpenes were near zero. GC-MS analysis showed that terpenoid emissions from the $Q$. ilex specimen used for this experiment were dominated by $\alpha$-pinene, $\beta$-pinene, and sabinene and that camphene and $\alpha$-thujene were also present in measurable quantities; these results were in agreement with the earlier work of Staudt and Seufert (1995). The monoterpene concentration leaving the aerosol growth chamber fluctuated with the plant's light exposure as well, dropping to almost zero overnight before increasing back to $\sim 5 \mathrm{ppb}$ the next day. Ozone varied inversely to the monoterpene concentration, reaching a maximum of $48 \mathrm{ppb}$ overnight, but decreasing to $\sim 44 \mathrm{ppb}$ as the VOC emissions increased again during the day. 

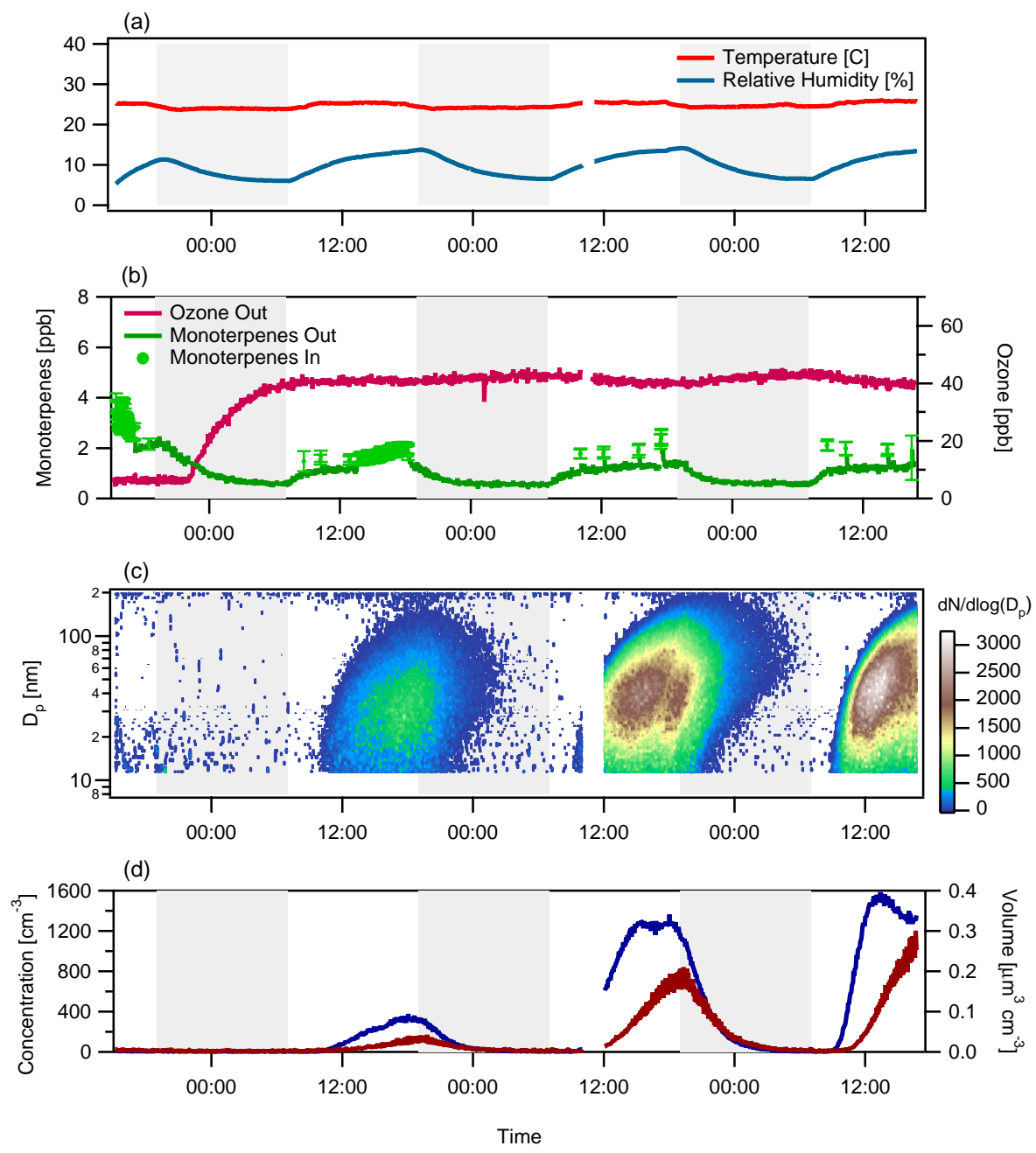

Fig. 5. Same as Fig. 4, but for the P. taeda experiment. The two-hour gap in the data was caused by a temporary instrument malfunction. Note what appears to be a second particle formation event at $\sim 17: 00$ on the second day of the experiment (see text).

Two particle formation events were observed during the Q. ilex experiment (Fig. 4c-d). The first occurred at $\sim 15: 00$ local time, approximately three hours after the initial addition of ozone. The number of particles formed was small relative to the $\alpha$-pinene experiment; the maximum particle concentration during the first event was $\sim 50 \mathrm{~cm}^{-3}$. At the end of the photoperiod (at 19:00 local time), when the plant specimen presumably stopped emitting monoterpenes, the particle concentration immediately began to decrease. It was nearly zero by midnight. The monoterpene concentration began to increase again soon after the light was restored at 06:00 the next morning, and three hours later the second particle formation event began. This event reached a maximum particle concentration of $60 \mathrm{~cm}^{-3}$, and the mode diameter for both events was $\sim 40 \mathrm{~nm}$. Particle growth rates for the two formation events were $\sim 10$ and $\sim 7 \mathrm{~nm} \mathrm{~h}^{-1}$, respectively. The experiment was terminated at 17:00, making the duration of the $Q$. ilex experiment $25 \mathrm{~h}$ total.

\subsection{Loblolly pine (Pinus taeda)}

The data from the P. taeda experiment are presented in Fig. 5. The duration of the $P$. taeda experiment was much longer than the previous experiments. It lasted $74 \mathrm{~h}$, which allowed several day/night cycles to be observed. The temperature and relative humidity inside the aerosol growth chamber behaved as they had during the $Q$. ilex experiment (Fig. 5a). The temperature oscillated between $\sim 297 \mathrm{~K}$ at night and $\sim 299 \mathrm{~K}$ during the day, while the relative humidity moved from $\sim 5 \%$ each night to $\sim 15 \%$ during the day, in response to the plant specimen's transpiration cycle.

During this experiment, ozone was first added to the growth chamber during the night. VOC emissions were lower during this period, due to the temperature decrease associated with the darkened bag and to the presumed reduction in light dependent sesquiterpenes. Both monoterpene (Fig. 5b) and sesquiterpene (Fig. 6) emissions were observed 


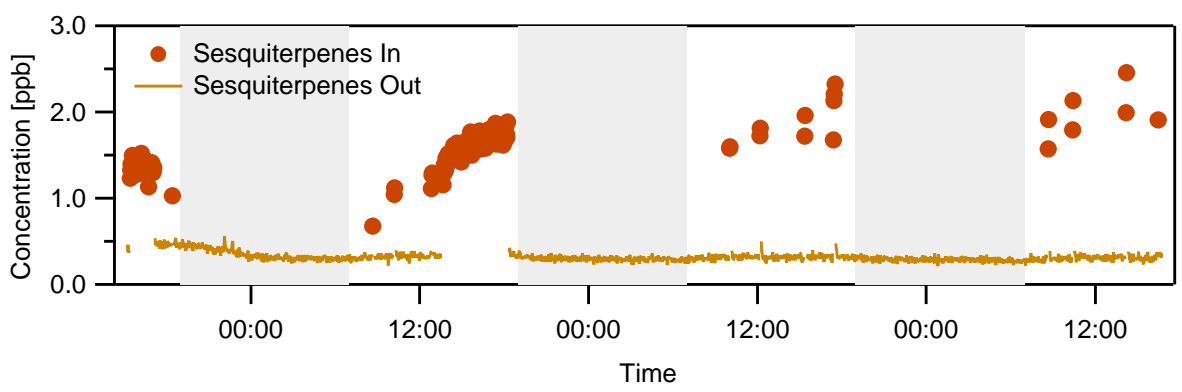

Fig. 6. Sesquiterpene concentrations from the P. taeda experiment. The sensitivity of the PTR-MS to sesquiterpenes has not been determined, so the conversion from normalized counts to concentration was estimated as described by Greenberg et al. (2006). Red circles show the VOC emissions entering the chamber. The orange solid line shows the amount of sesquiterpenes in the stream exiting the chamber, at background noise levels.

from the specimen. A cartridge collected during the second day of the experiment and analyzed using GC-MS indicated that the monoterpenes emitted included $\alpha$-pinene, $\beta$ pinene, limonene, ocimene, myrcene, and camphene. Also emitted were the sesquiterpenes $\beta$-caryophyllene and humulene. From the input and output monoterpene concentrations in Fig. 5b, it can be inferred that the monoterpene emissions increased each morning to $\sim 1 \mathrm{ppb}$, and then more gradually increased to $\sim 2 \mathrm{ppb}$ over the rest of the day.

The same trends observed in the monoterpene emissions can be seen in the sesquiterpene emissions also. Figure 6 shows the sesquiterpene signal from the PTR-MS. As with the monoterpenes, the limited data indicates that the sesquiterpene concentration increases to $\sim 2 \mathrm{ppb}$ over the course of the day. It reacts completely within the aerosol growth chamber; the output concentration remains at the background noise threshold throughout the experiment. It should be noted that these sesquiterpene concentrations are more highly uncertain than the reported monoterpene concentrations: the sensitivity of the instrument to sesquiterpenes has not been determined, so the conversion from normalized counts to concentration must be estimated. The considerations involved in this estimation were described by Greenberg et al. (2006), and the result has an uncertainty of roughly a factor of two. No sesquiterpene signal was observed during either the $\alpha$-pinene or the $Q$. ilex experiment.

Even with the contribution from sesquiterpenes included, the total terpenoid concentration was only about half of that measured during the other two experiments. Despite this, particle formation events occurred during each of the three days of the P. taeda experiment. Moreover, on two of the days, the magnitude of the formation event was greater than those observed during the previous experiments. The maximum particle concentrations for the three days were 300 , 1200 , and $1400 \mathrm{~cm}^{-3}$, respectively. In each case the particle formation began three hours after the branch was illuminated (which coincided approximately with the small temperature increase in the aerosol growth chamber). On the first two days, the mode diameter when the particle concentra- tion reached its maximum was $40 \mathrm{~nm}$. The event was somewhat more intense on the final day, when the mode diameter reached $50 \mathrm{~nm}$, and the peak particle concentration occurred earlier in the day. Particle growth rates for the three formation events were approximately 3,4 , and $10 \mathrm{~nm} \mathrm{~h}^{-1}$, respectively.

As in the $Q$. ilex experiment, the formation cycle terminated each night when the light turned off and the temperature decreased, thereby reducing the VOC emissions. At that point, the aerosol concentration decreased steadily throughout the evening and the growth chamber was essentially free of particles by the next morning. However, on the latter two days of the P. taeda experiment, the peak particle concentration occurred several hours before the experiment was terminated. In fact, on the second day, there was evidence of a second, distinct particle formation event occurring in late afternoon (cf. Fig. 5c). These results suggest that, as in the $\alpha$-pinene experiment, the condensational sink periodically dominated particle formation to the degree that particles were being removed from the system faster than they were being formed.

\section{Discussion}

The experiments described here emphasize the variability inherent in new particle formation from biogenic sources. When exposed to similar conditions in terms of temperature, relative humidity, and ozone, the oxidation of $Q$. ilex specimen emissions resulted in far less new particle formation than did a smaller concentration of pure $\alpha$-pinene. The oxidation of $P$. taeda specimen emissions resulted in more particles than either, despite significantly lower terpenoid concentrations. The monoterpene concentrations entering the aerosol growth chamber during these experiments were much lower than those used in most chamber studies, and approached those encountered in the ambient atmosphere surrounding canopies dominated by $P$. taeda (Stroud et al., 2005) or Q. ilex (Schween et al., 1997). 
From the results available here, it is not possible to determine conclusively the mechanism leading to the formation of new particles. In general, however, the data agree with earlier studies. While it is somewhat surprising that there was such a large difference in the amount of aerosol produced during the $Q$. ilex experiment when compared with $\alpha$-pinene, a likely explanation is found in the composition of the emissions from the $Q$. ilex specimen. According to the GC-MS analysis, $\alpha$-pinene accounted for only $\sim 40 \%$ of the monoterpenes emitted from the $Q$. ilex specimen. Another $40 \%$ was $\beta$-pinene, and the previously mentioned compounds accounted for the rest. $\beta$-pinene is known to react much more slowly than $\alpha$-pinene (Griffin et al., 1999b), and given the relatively short residence time in the growth chamber, only a small fraction of the $\beta$-pinene would have reacted. This would of course lead to the formation of less condensable material, which is consistent with the observed smaller particle formation event. At the opposite extreme, the large particle formation events observed during the $P$. taeda experiment are consistent with rapid reaction of sesquiterpenes to condensable products, which may contribute directly to the nucleation process, as suggested by Bonn and Moortgat (2003). These results are interesting but it should be noted that the results presented here are from single experiments involving single specimens; replication of the experiments using additional specimens is necessary in order to quantify the observed variability.

Other behavior ovserved during this study cannot be readily explained, even in a qualitatitve sense. For example, it is unclear why during the $P$. taeda experiment there was such variation in the magnitude of the particle formation event under seemingly similar experimental conditions. It is possible that the composition of the biogenic emissions changed from one day to the next, perhaps due to added stress on the plant specimen. Another possibility is that, as suggested by Goldstein et al. (2004) and Holzinger et al. (2005), some gas species in addition to those observed during the study contributed to the particle formation event and varied during the experiment. Future studies will measure additional trace gas properties in effort to better characterize the system.

This study has demonstrated the ability to form aerosol directly from biogenic emissions under conditions that approach the ambient atmosphere. As had been expected, the magnitude of the particle formation event varied considerably between the species examined here. The facility developed for this work will be a valuable tool for examining the mechanisms leading to new particle formation from biogenic sources, and for characterizing the properties of aerosols resulting from such formation events.

Acknowledgements. The National Center for Atmospheric Research is sponsored by the National Science Foundation. Support for this work at NCAR was provided by the Advanced Study Program and the Opportunity Fund.

Edited by: A. Laaksonen

\section{References}

Andreae, M. O. and Crutzen, P. J.: Atmospheric aerosols: biogeochemical sources and role in atmospheric chemistry, Science, 276(5315), 1052-1058, 1997.

Badger, E. H. M. and Dryden, I. G. C.: The formation of gum particles in coal-gas, Trans. Faraday Soc., 35, 607-628, 1939.

Bonn, B. and Moortgat, G. K.: New particle formation during $\alpha$ and $\beta$-pinene oxidation by $\mathrm{O}_{3}, \mathrm{OH}$, and $\mathrm{NO}_{3}$, and the influence of water vapour: particle size distribution studies, Atmos. Chem. Phys., 2, 183-196, 2002, http://www.atmos-chem-phys.net/2/183/2002/.

Bonn, B. and Moortgat, G. K.: Sesquiterpene ozonolysis: origin of atmospheric new particle formation from biogenic hydrocarbons, Geophys. Res. Lett., 30(11), 1585, doi:10.1029/2003GL017000, 2003.

Boy, M., Hellmuth, O., Korhonen, H., Nillson, D., ReVelle, D., Turnipseed, A., Arnold, F., and Kulmala, M.: MALTE model to predict new aerosol formation in the lower troposphere, Atmos. Chem. Phys. Discuss., 6, 3465-3512, 2006,

http://www.atmos-chem-phys-discuss.net/6/3465/2006/.

Claeys, M., Graham, B., Vas, G., Wang, W., Vermeylen, R., Pashynska, V., Cafmeyer, J., Guyon, P., Andreae, M. O., Artaxo, P., and Maenhaut, W.: Formation of secondary organic aerosol through photooxidation of isoprene, Science, 303(5661), 11731176, 2004.

Crump, J. G. and Seinfeld, J. H.: Turbulent deposition and gravitational sedimentation of an aerosol in a vessel of arbitrary shape, J. Aerosol Sci., 12, 405-415, 1981.

Fuch, M. A.: The Mechanics of Aerosols, Pergamon Press, New York, 1964.

Goldstein, A. H., McKay, M., Kurpius, M. R., Schade, G. W., Lee, A., Holzinger, R., and Rasmussen, R.: Forest thinning experiment confirms ozone deposition to forest canopy is dominated by reaction with biogenic VOC, Geophys. Res. Lett., 31, L22106, doi:10.1029/2004GL021259, 2004.

Greenberg, J. P., Guenther, A., Zimmerman, P., Baugh, W., Geron, C., Davis, K., Helmig, D., and Klinger, L. F.: Tethered balloon measurements of biogenic VOCs in the atmospheric boundary layer, Atmos. Environ., 33(6), 855-867, 1999.

Greenberg, J. P., Friedi, H., Guenther, A. B., Hanson, D., Harley, P., and Karl, T.: Volatile organic emission fro the distillation and pyroloysis of vegetation, Atmos. Chem. Phys., 6, 81-91, 2006, http://www.atmos-chem-phys.net/6/81/2006/.

Griffin, R. J., Cocker, D. R., Seinfeld, J. H., and Dabdub, D.: Estimate of global atmospheric organic aerosol from oxidation of biogenic hydrocarbons, Geophys. Res. Lett., 26(17), 2721-2724, 1999a.

Griffin, R. J., Cocker, D. R., Flagan, R. C., and Seinfeld, J. H.: Organic aerosol formation from the oxidation of biogenic hydrocarbons, J. Geophys. Res., 104(D3), 3555-3567, 1999b.

Hansen, U. and Seufert, G.: Temperature and light dependence of beta-caryophyllene emission rates, J. Geophys. Res., 108(D24), 4801, doi:10.1029/2003JD003853, 2003.

Hanson, D., Greenberg, J. P., Henry, B., and Kosciuch, E.: Proton transfer reaction mass spectroscopy at high drift tube pressure, Int. J. Mass Spec., 23(1-3), 507-518, 2002.

Holzinger, R., Lee, A., Paw, U. K. T., and Goldstein, A. H.: Observations of oxidation products above a forest imply biogenic emissions of very reactive compounds, Atmos. Chem. Phys., 5, 
67-75, 2005,

http://www.atmos-chem-phys.net/5/67/2005/.

Intergovernmental Panel on Climate Change (IPCC): Climate Change: The Scientific Basis, Cambridge University Press, UK, 2001.

Joutsensaari, J., Loivamäki, M., Vuorinen, T., Miettinen, P., Nerg, A.-M., Holopainen, J. K., and Laaksonen, A.: Nanoparticle formation by ozonolysis of inducible plant volatiles, Atmos. Chem. Phys., 5, 1489-1495, 2005,

http://www.atmos-chem-phys.net/5/1489/2005/.

Kanakidou, M., Seinfeld, J. H., Pandis, S. N., Barnes, I., Dentener, F. J., Facchini, M. C., Van Dingenen, R., Ervens, B., Nenes, A., Nielsen, C. J., Swietlicki, E., Putaud, J. P., Balkanski, Y., Fuzzi, S., Horth, J., Moortgat, G. K., Winterhalter, R., Myhre, C. E. L., Tsigaridis, K., Vignati, E., Stephanou, E. G., and Wilson, J.: Organic aerosol and global climate modelling: a review, Atmos. Chem. Phys., 5, 1053-1123, 2005, http://www.atmos-chem-phys.net/5/1053/2005/.

Karl, T., Harley, P., Guenther, A., Rasmussen, R., Baker, B., Jardine, K., and Nemitz, E.: The bi-directional exchange of oxygenated VOCs between a loblolly pine (Pinus taeda) plantation and the atmosphere, Atmos. Chem. Phys., 5, 3015-3031, 2005, http://www.atmos-chem-phys.net/5/3015/2005/.

Kroll, J. H., Ng, N. L., Murphy, S. M., Flagan, R. C., and Seinfeld, J. H.: Secondary organic aerosol formation from isoprene photooxidation under high-NOx conditions, Geophys. Res. Lett., 32, L18808, doi:10.1029/2005GL023637, 2005.

Kulmala, M., Vehkamäki, H., Petäjä, T., Dal Maso, M., Lauri, A., Kerminen, V.-M., Birmili, W., and McMurry, P. H.: Formation and growth rates of ultrafine atmospheric particles: a review of observations, J. Aerosol Sci., 35(2), 143-176, 2004.

Levenspiel, O.: Chemical Reaction Engineering, John Wiley \& Sons, New York, 1972.

Lindinger, W., Hansel, A., and Jordan, A.: On-line monitoring of volatile organic compounds at pptv levels by means of protontransfer-reaction mass spectrometry (PTR-MS) - medical applications, food control and environmental research, Int. J. Mass Spectrom., 173(3), 191-241, 1998.
McFiggans, G., Coe, H., Burgess, R., Allan, J., Cubison, M., Alfarra, M. R., Saunders, R., Saiz-Lopez, A., Plane, J. M. C., Wevill, D. J., Carpenter, L. J., Rickard, A. R., and Monks, P. S.: Direct evidence for coastal iodine particles from Laminaria macroalgae - linkage to emissions of molecular iodine, Atmos. Chem. Phys., 4, 701-713, 2004, http://www.atmos-chem-phys.net/4/701/2004/.

McGraw, R. and Saunders, J. H.: A condensation feedback mechanism for oscillatory nucleation and growth, Aerosol Sci. Technol., 3(4), 367-380, 1984.

Schween, J. H., Dlugi, R., Hewitt, C. N., and Foster, P.: Determination and accuracy of VOC-fluxes above the pine/oak forest at Castelporziano, Atmos. Environ., 31 199-215, 1997.

Staudt, M., Mandl, N., Joffre, R., and Rambal, S.: Intraspecific variability of monoterpene composition emitted by Quercus ilex leaves, Canadian Journal of Forest Research, 31(1), 174-180, 2001.

Staudt, M. and Seufert, G.: Light-dependent emission of monoterpenes by Holm oak (Quercus ilex L.), Naturwissenschaften, 82(2), 89-92,1995.

Stroud, C., Makar, P., Karl, T., Guenther, A., Geron, C., Turnipseed, A., Nemitz, E., Baker, B., Potosnak, M., and Fuentes, J. D.: Role of canopy-scale photochemistry in modifying biogenicatmosphere exchange of reactive terpene species: results from the CELTIC field study, J. Geophys. Res., 110, D17303, doi:10.1029/2005JD005775, 2005.

VanReken, T. M., Ng, N. L., Flagan, R. C., and Seinfeld, J. H.: Cloud condensation nucleus activation properties of biogenic secondary organic aerosol, J. Geophys. Res., 110, D07206, doi:10.1029/2004JD005465, 2005.

Yu, J. Z., Cocker, D. R., Griffin, R. J., Flagan, R. C., and Seinfeld, J. H.: Gas-phase ozone oxidation of monoterpenes: gaseous and particulate products, J. Atmos. Chem., 34(2), 207-258, 1999. 